\title{
Nota de la Editora
}

El Anuario de Derechos Humanos 2012 tiene distintas innovaciones respecto de los números de años anteriores. El cambio más relevante es sin duda la realización, por primera vez, de una convocatoria abierta para la recepción de artículos: un tercio de los artículos del Anuario han sido seleccionados de esta manera, y esto marca ciertamente una nueva fase de esta publicación que tiene ya ocho años de existencia. En esta convocatoria, que se limitó a las secciones Nacional e Internacional, tuvimos la oportunidad de considerar artículos que provenían tanto de América Latina como de Europa, de países tan diversos como Alemania, Argentina, Bélgica, Bolivia, Brasil, Chile, Colombia, Paraguay, Perú, Reino Unido y Venezuela.

Sometimos 33 de estos artículos a la revisión anónima de dos evaluadores externos. Fueron 30 las y los experto/as provenientes de nueve países de la región los que integraron nuestro Comité de Evaluadores. Muchos de las y los evaluadores son reconocidos especialistas en su área y buena parte de ellos son destacados y destacadas ex alumno/as de los numerosos Diplomas de Postítulo que el Centro de Derechos Humanos $(\mathrm{CDH})$ ha impartido en toda la región. Esto demuestra la consolidación que han tenido tanto el $\mathrm{CDH}$ como el Anuario a nivel internacional, y es un exitoso ejemplo de la sinergia positiva que se ha logrado construir entre las actividades del Centro, en tanto la formación y las redes que se han creado a través de la docencia son luego aprovechadas como una herramienta esencial para mejorar la calidad de nuestras publicaciones.

Como editora, pude constatar el entusiasmo de las y los autores, la excelente disposición y el rigor de las y los evaluadores -los que realizaron estas actividades de forma gratuita-, así como la buena recepción que tuvieron las evaluaciones en los autores, y que, respecto de los artículos que finalmente fueron publicados, contribuyeron de forma fundamental a mejorar su calidad académica. En definitiva, esta primera experiencia de convocatoria del Anuario mostró la mejor cara de un proceso de creación y difusión de conocimiento en el ámbito académico.

También cabe destacar la excelente disposición de los y las autoras a quienes invitamos especialmente a escribir en el Anuario en las secciones que no fueron cubiertas por la convocatoria: el que destacado/as especialistas, ya consagrado/as en sus disciplinas, entreguen también de forma completamente desinteresada su tiempo y su energía en realizar valiosas contribuciones a nuestra revista es una renovada prueba del prestigio del Anuario y de la solidez de las redes académicas del $\mathrm{CDH}$.

Otros cambios en la edición 2012 del Anuario dicen relación con la introducción del título, resumen y palabras clave de cada artículo en inglés, lo que tiene por objetivo lograr una mayor difusión de los mismos. Esto, porque desde este año el Anuario se incorpora al Portal de Revistas Académicas de la Universidad de Chile, una plataforma digital que agrupa todas las revistas de nuestra casa de estudios y que busca aumentar tanto la calidad como la visibilidad de sus publicaciones. De esta forma, la versión digital del Anuario puede encontrarse ingresando tanto desde 
la página web del Centro (www.cdh.uchile.cl) como a través de la propia página del Anuario en el Portal de Revistas (www.anuariocdh.uchile.cl).

Todos estos cambios de forma están por supuesto al servicio de hacer más accesible el contenido de esta nueva edición del Anuario.

El Anuario 2012 recoge los principales desarrollos en materia de derechos humanos acaecidos durante el año anterior a su publicación. El 2011 fue un año particularmente intenso para los derechos humanos, pues amplios movimientos sociales se alzaron en distintas partes del mundo para reclamar inclusión y participación. Y tanto la inclusión de los sectores más marginalizados como la participación de la ciudadanía en los asuntos públicos son dos temas que cruzan transversalmente esta edición del Anuario.

La sección de Doctrina de este año fue dedicada al apremiante problema de las cárceles: las personas privadas de libertad forman parte de los sectores más excluidos, y respecto de quienes la exclusión se encuentra más justificada y naturalizada en nuestras sociedades. Andrew Coyle y Elías Carranza -probablemente dos de los especialistas más reconocidos en el área de estudios penitenciarios- nos entregan un panorama tanto de los estándares internacionales aplicables, como de la situación carcelaria a nivel regional. Para ambos, la clave para abordar la dramática situación de las cárceles es una robusta concepción de la dignidad humana y, por sobre todo, menos exclusión y mayor equidad social.

Sin embargo, no existe inclusión sin participación. Por ello, el Simposio sobre Participación Política en América Latina buscó recoger el tenor de esta discusión, y tuvimos el privilegio de contar con contribuciones del más alto nivel y de una riquísima diversidad social y geográfica: desde la academia, contamos con Alberto J. Olvera, de México, y con Maristella Svampa, de Argentina, así como con Alex Shankland, de Inglaterra, quien ha trabajado el caso de Brasil. Estos tres investigadores han estudiado y escrito extensamente sobre los problemas de democratización, participación, protesta social e inclusión, y nos entregan una visión muy rica sobre los desafíos actuales en estas materias en América Latina. Asimismo, Arturo Squella -como diputado- y Camila Vallejo -como dirigente estudiantil-, ambos de Chile, pero desde diversas veredas políticas, nos entregan su mirada como actores del intenso debate que se está dando sobre la participación en nuestro país.

La Sección Internacional también aborda la necesidad de reafirmar la inclusión de ciertos sectores que han sido históricamente dejados de lado: el artículo de Catalina Uprimny sobre la memoria en la Ley de Víctimas en Colombia se pregunta justamente sobre la adecuada incorporación de la memoria de las víctimas en esta ley pionera. En un mismo sentido, Rafael Oliveira do Prado nos introduce al recientemente dictado Convenio 189 de la OIT que regula, finalmente, la situación de los trabajadores y trabajadoras domésticos, poniendo especial énfasis en las trabajadoras domésticas migrantes, un grupo en particular condición de vulnerabilidad. Simón Conforti analiza la nueva Observación General del Comité de Derechos Humanos de Naciones Unidas sobre libertad de expresión. Esta resolución demuestra la consolidación de los estándares ya existentes en la materia, aunque los avances del Comité parecen tímidos respecto de los adelantos tecnológicos que han permitido la incorporación de amplios grupos de personas que antes no participaban del debate público, lo que crea nuevos escenarios y desafíos para la libertad de expresión. Por su parte, dos artículos nos confrontan con los límites del ámbito de acción de los tribunales internacionales y, en esta materia, la Corte Interamericana y la Corte Europea de Derechos Humanos parecen moverse en direcciones opuestas: el artículo de Juana María Ibáñez muestra cómo la reafirmación de la doctrina del control de convencionalidad en el marco de la jurisprudencia de la Corte Interamericana apunta a lograr una incorporación cada vez mayor de los estándares internacionales a nivel interno. Por el contrario, en el marco de la Corte Europea, el análisis de 
Francisco Javier Mena sobre la sentencia en el caso $A, B$ y $C$ vs. Irlanda parece augurar una ampliación del "margen de apreciación" de los Estados y una correlativa inhibición del control que estaría Ilamado a realizar dicho Tribunal.

En la Sección Nacional, inclusión y participación son nuevamente los dos grandes ejes en torno a los cuales se articula el debate en el caso de Chile. Las masivas manifestaciones públicas que sacudieron a nuestro país en 2011 pusieron en duda el grado en que el derecho a reunirse y manifestarse se encuentra garantizado: Branislav Marelic realiza un diagnóstico de las diversas violaciones a derechos y libertades de las que pudo ser testigo en las marchas estudiantiles, y relata su experiencia de exponer estas infracciones del Estado chileno ante la Comisión Interamericana de Derechos Humanos. Por otro lado, los artículos de Gonzalo Berríos y de Jorge Contesse nos confrontan con la forma en que los tribunales de diverso rango reafirman exclusiones y discriminaciones: los tribunales penales en la aplicación de la Ley Antiterrorista a los adolescentes mapuche -a pesar de una disposición legal expresa que excluía a los menores de 18 años de la aplicación de esta Ley-; y el Tribunal Constitucional, al no considerar que el principio de igualdad requería pronunciarse sobre la ampliación de la institución del matrimonio a parejas del mismo sexo. Por último, Lorena Fries, la actual directora del Instituto Nacional de Derechos Humanos, realiza un diagnóstico de los desafíos que se presentan para esta institución en sus primeros años: los retos estarían en conciliar las visiones del derecho interno con las del derecho internacional; los combates del pasado con las luchas del presente y los derechos civiles con los económicos y sociales; así como consolidar una concepción fuerte de igualdad que permita la inclusión de colectivos que requieren de un trato diferenciado.

En los Temas en Debate el leitmotiv de la inclusión se refleja en el artículo de Carlos Ruiz sobre derecho a la educación en Chile: este tema es retomado por el autor no desde la contingencia, sino desde una perspectiva filosófica e histórica, trazando la reflexión que en el ámbito de la ética y la filosofía política occidental justifican la existencia de un derecho a una educación pública y gratuita, y evaluando las consecuencias de estas ideas en el caso de Chile. Por su parte, Leonardo Filippini, a través de su análisis de la sentencia de la Corte IDH en el caso Gelman, evalúa el problema que se presenta cuando las instancias de representación popular -como el plebiscito que no logró anular la amnistía a los militares uruguayos- contradicen el imperativo de justicia y castigo en casos de graves violaciones a los derechos humanos. La clave del autor para leer este caso es, sin embargo, desplazada hacia una valoración del reconocimiento de responsabilidad por parte del Estado, en el contexto de una transición tardía.

Por último, la Entrevista que, junto con Marcela Sandoval, pudimos realizar al reconocido historiador de la Universidad de Wisconsin-Madison, Steve J. Stern, cierra este número, pues su trabajo sobre memoria en Chile y su visión amplia de la historia latinoamericana integra la mayoría de los tópicos que se trataron en las distintas secciones del Anuario: cómo el pasado y la memoria marcan los desafíos para avanzar en derechos humanos en el presente; la importancia de un diálogo intergeneracional; cómo una amplia concepción de la participación es la forma de permitir sinergias positivas entre Estado y sociedad civil; cómo las manifestaciones de los jóvenes por una mejor educación apelan a una demanda de inclusión y a un renovado esfuerzo por garantizar derechos sociales; y cómo, finalmente, el trabajo en derechos humanos requiere de ciertas definiciones morales y políticas, así como de un trabajo interdisciplinario que permita abordar sus múltiples aristas sin perder nunca la perspectiva humana.

Este es un último punto que quisiera recalcar en los contenidos de este Anuario: la multidisciplinariedad de sus autores y por lo tanto de los enfoques. En este número escriben muchos juristas, pero también un criminólogo, varios sociólogo/as y cientistas políticos, un historiador, un filósofo, una periodista y una geógrafa. Todo/as tienen valiosísimas visiones que aportar, lo que reafirma una vez más que los derechos humanos no son ni deben ser un patrimonio de los abogados. 
Finalmente, quiero terminar agradeciendo a Claudio Nash y a Cecilia Medina el voto de confianza en nombrarme editora de este número del Anuario, así como su esencial apoyo en todas las etapas de su publicación. Agradezco igualmente a Patricia Palacios, quien tradujo los resúmenes de los artículos al inglés, así como a Alia Trabucco, quien tradujo al español dos contribuciones a este Anuario y cuyo trabajo impecable hizo casi innecesario un ulterior trabajo de edición sobre ellos. Agradezco igualmente a las y los colegas en el Centro de Derechos Humanos, pues de todo/as he requerido ayuda o apoyo en el largo proceso de publicación del Anuario, y en particular a Rayen Campusano, ayudante del $\mathrm{CDH}$, quien participó de la corrección final de los manuscritos y a Catalina Milos, quien me ayudó a tomar decisiones y resolver muchas dudas a lo largo de todo el proceso de edición. Y reitero, finalmente, mi inmensa gratitud a las y los evaluadores cuyos comentarios fueron fundamentales en la selección y corrección de los artículos, así como, por supuesto, a las y los autores, quienes hicieron don de su tiempo, inteligencia y dedicación: son ellos quienes hacen posible que este libro exista.

\section{Marianne González Le Saux}

Editora, Anuario 2012. 